\title{
Effects Of A Problem-Solving-Based Mathematics Course On Number Sense Of Preservice Teachers
}

\author{
Yea-Ling Tsao (E-mail: tsao@ocit.edu.tw), The Overseas Chinese Institute of Technology, Taiwan
}

\begin{abstract}
The purpose of this study was to investigate what level of number sense was possessed by preservice elementary school teachers. The sample was composed of students in six intact entry-level mathematics sections of a course populated by preservice elementary school teachers. One hundred fifty-five participants from these six classes completed data collection tasks during the Spring 2002 semester for the study. These courses are all problem-solving-based. A problemsolving-based mathematics course was designed to utilize manipulatives, problem solving approaches, and the cooperative learning environment. Students actively participate in problemsolving mathematical exploration. Research designs using a control group could not be used for this study, as the problem-solving-based classroom is the required method by the institution to teaching this mathematics class. The six combined classes form "one-group" with pretest/posttest corresponding to the pre-post-surveys. T-tests were used to compare the paired changes in number sense across time.The participating elementary school preservice teachers' number sense changed between the beginning and the completion of the undergraduate mathematics content course. This change was significant at $\alpha=0.01$ for issues.
\end{abstract}

\section{Introduction}

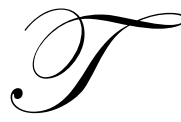

he development of number sense is important in mathematics education. The National Council of Teachers of Mathematics, in their Principles and Standards for School Mathematics, note that number sense is one of the foundational ideas in mathematics in that students (1) Understand number, ways of representing numbers, relationships among numbers, and number system; (2) Understand meanings of operations and how they related to one another; (3) Compute fluently and make reasonable estimates. (NCTM, 2000, p32).

Considerable research has dealt with the mathematical performance of elementary school students, but far less research has dealt with what their teachers understand. The few studies that have investigated the mathematical understanding of elementary teachers and preservice elementary teachers indicate that many exhibit weakness in mathematics, may misapply mathematical rules, do not understand true meanings of mathematical concepts, and that they are, generally, not prepared to teach the mathematical subject matter entrusted to them (Cuff, 1993; Hungerford, 1994). In that elementary teachers provide the first formal mathematical training children receive, it is reasonable that the educators responsible for preparing them to teach should know what skills they possess and what skills they lack in order to design their curriculum. It is also reasonable to assume that, if the perceptions and misconceptions teachers possess are addressed during preservice training, or even during inservice training, their teaching performance will be strong.

A mathematics course designed for preservice elementary teachers may be the best setting for the study of their understanding of number sense. This study will focus on the preservice teacher in a problem-solving-based mathematics course that includes the study of number sense. Of particular interest is the preservice teachers' entrylevel understanding of number sense and their proficiency with it at the end of the course. 
In many cases, however, much of the attention to developing number sense is a reaction to an over emphasis on computational procedures that are often algorithmic and devoid of number sense. For instance, the reaction of a student when asked if a calculation seems reasonable is often to recalculate rather than to reflect on the result in the light of context and numbers involved (Wyatt,1986). Mclnotosh et al. (1992) claimed that high skill in written computation is not necessarily accompanied by number sense. This finding confirms that the content emphasized in mathematics is what is learned and is consistent with the statements (Sowder,1988, p. 227) that "correct answers are not a safe indicator of good thinking" and "teachers must examine more than answers and must demand from students more than answers." Johnson (1998) found that preservice elementary teachers have a gap in their rational number understanding and that they rely on the use of algorithms when approaching non-standard problems. The misconceptions they exhibit tend to be similar across different representations of rational numbers. The findings of Rasch (1992) and Hungerford (1994) suggest that preservice elementary school teachers exhibit difficulties with rational numbers that may be indicative of a lack of intuitive conceptual understanding of the meaning and properties of the number system. Thus, the scope of number sense was restricted to the understandings that could be derived mentally, without resorting to computation, rules, or algorithms.

Although considerable attention to number sense is occurring in the United States, the term "number sense" is rarely heard in preservice teacher research. Believing that understanding the level of number sense should play an important role in preservice teaching programs, the motive for conducting this study rises from a deep concern for the development of number sense for preservice teachers.

\section{The Purpose Of The Study}

The purpose of this study was to investigate what level of number sense was possessed by preservice elementary school teachers. The institution used in this study has recently implemented an undergraduate program that requires all prospective elementary school teachers to take a three-semester sequence of mathematics courses. These courses are all problem-solving-based. A problem-solving-based mathematics course was designed to utilize manipulatives, problem solving approaches, and cooperative learning environment. Students actively participate in problem-solving mathematical exploration. The focus of the teaching was student thinking and mathematical activity. The students (mostly preservice elementary school teachers) take part in hands on activities utilizing manipulatives and technology (McNernery, 1994 ), learning mathematical ideas in much the same way elementary school students learn mathematics under a standard-based curriculum.

The first course addresses number sense in many content areas. This introductory course provides the opportunity for investigating the number sense of preservice elementary school teachers, as well as the opportunity to look at the effects the course has on the number sense of its students. Artzt (1999) notes that with cooperative learning, such as that in a problem-solving-based classroom, students have the opportunity to discuss mathematical problems with group members because their attitudes make them feel more comfortable and reassured. Furthermore Quinn (1998) found that preservice teachers learn mathematical content through the use of manipulatives in mathematics methods courses. This study intends to look at the change in the number sense of preservice elementary school teachers during the semester they are enrolled in the first undergraduate mathematics course of the sequence.

\section{Research Questions And Hypotheses}

What are the effects of a problem-solving-based mathematics course on the number sense of preservice elementary school teachers? A quantitative approach will be used to address the question, with the following null hypotheses:

$\mathbf{H}_{\mathbf{0 1}}$ : There is no significant difference in the measures of preservice elementary school teachers number sense collected at the beginning and end of the problem-solving-based mathematics course, at the $\alpha=0.01$ level. 


\section{Review of Literature}

The literature reviewed for this study will begin with the foundation of number sense and then define number sense. The second section focuses on discussing number sense related to preservice teachers. The Final section includes, a discussion of instruction related to improvement of number sense from the constructivism perspective.

\section{Foundation Of Number Sense}

In the 1930's, William Brownell considered learning had taken place only when an individual was able to grasp number relationship and deal with arithmetical situations with comprehension (Reys, 1994). The Commission on Standards for School Mathematics of NCTM, in 1987, described children with number sense as those children who understand number meaning, develop multiple relationships among numbers, know relative sizes of numbers, and comprehend how arithmetic operations affect results (Howden, 1989). The development of number sense is guided by a child's informal knowledge of numbers and quantity. Children need to be provided with problem solving opportunities that build on their own knowledge. Researchers have shown that the concept of number and number operation develops over time (Resnick, 1983; Hiebert, Carpenter \& Moser; 1982; Reys, Reys, Nohda \& Emori , 1995; Reys \& Yang, 1998, McIntosh, B. Reys, \& R.Reys, 1992; Sowder \&McIntosh , 1994). Marshall (1989) defined number sense as "the richness of conceitedness of mathematical knowledge."

By referring to how number sense was exhibited, Greeno (1991) characterized number sense in terms of flexible mental computation, numerical estimations and qualitative judgments. His perspective on number sense encompassed recognition of the role of equivalence in the decomposition/recomposition of numbers, the use of approximate numeric values in computational contexts and the making of inferences and judgments about quantities with numerical values. Greeno (1989) characterized those with good number sense as being able to navigate in a number environment as one who is familiar with their surroundings.

Kaminski (1997) found that the use of number sense can assist individuals in their understanding of, and calculation in, mathematics. He reported on these aspects of number sense by studying six primary preservice teacher education students. Kaminski chose those who experienced difficulties with whole and rational number numeration and computation in addition to those who exhibited a desire to understand more about students' use of number sense. The researcher found the preservice teacher students in this study displayed underdeveloped sense of number, exhibited a preference for using exact written calculations and seldom utilized approaches involving estimation, and desired to follow a set line of reasoning without reviewing the appropriateness of the strategies employed or reasonableness of results obtained. One description which provides a useful perspective on number sense is that offered by Howden (1989) : Number sense can be described as a good intuition about number and their relationships. It develops gradually as a result of exploring numbers, visualizing them in a variety of contexts, and relating them in ways that are not limited by traditional algorithms (p. 11).

It seems intuitive that students who have more opportunities to learn and explore mathematics would develop greater number sense. The NCTM Curriculum and Evaluation Standards (1989) define that Children with good number sense (1) have well-understood number meaning, (2) have developed multiple relationships among numbers, (3) recognize the relative magnitude of numbers, (4) know the relative effect of operating on number, and (5) develop a referent for measures of common objects and situations in their environment (p. 38).

Three of these components-developing number meaning, understanding relative size of numbers, and developing familiar referents-may be considered understanding that is related to number sense. Exploring number relationships with manipulatives is a teaching method used to promote the student's development of number sense and other ideas. The last component, developing referents for measures of common objects and situations, utilize operation sense, as well as number sense. More broadly stated by Sowder (1994), number sense refers to: A well organized conceptual network that enables a person to relate number properties with operation properties. It can be recognized by the ability to compose and decompose numbers and move flexibly among different representations, to compare and order numbers, to use benchmarks to deal with absolute magnitude of numbers, to link numeration 
operations and relation symbols in a meaningful way, to mentally calculate and estimate using invented strategies, to understand the effects of operations on numbers, and to be disposed to make sense of number (p. 145).

McIntosh et al.(1992) developed a number sense framework based on research and reflection on the literature related to the topic. Components of number sense hypothesized by several researchers (Sowder \& Schapplle, 1989) were reviewed and analyzed, within the framework. Three broad categories emerged:

1. knowledge of and facility with numbers,

2. knowledge of and facility with operations, and

3. ability to apply knowledge of and facility with numbers and operations to computational sittings. See Table 1.

From the framework, six major components of number sense were identified (McIntosh et al. ,1999, p.62 ).

Table 1.

Six Components Of Number Sense

\begin{tabular}{|l|l|}
\hline \multicolumn{1}{|c|}{ Number Sense Component } & \multicolumn{1}{c|}{ Example } \\
\hline Understanding of the meaning and size of number & $\begin{array}{l}\text { How does } 2 / 5 \text { compare in size to } 1 / 2 ? \\
\text { How do you know? }\end{array}$ \\
\hline $\begin{array}{l}\text { Understanding and use of equivalent representations of } \\
\text { numbers }\end{array}$ & Show different ways that $2 / 5$ can be represented. \\
\hline Understanding the meaning and effect of operations & $\begin{array}{l}\text { Is } 750 \div 0.98 \text { more or less than } 750 ? \\
\text { How do you know? }\end{array}$ \\
\hline Understanding and use of equivalent expressions & $\begin{array}{l}\text { Are } 700 \div 0.5 \text { and } 70 \times 0.5 \text { equivalent? } \\
\text { How do you know? }\end{array}$ \\
\hline $\begin{array}{l}\text { Flexible computing and counting strategies for mental } \\
\text { computation, written computation, and calculators. }\end{array}$ & $\begin{array}{l}\text { Can you multiply } 6 \times 98 \text { mentally by using your understanding } \\
\text { of numbers and operations? }\end{array}$ \\
\hline $\begin{array}{l}\text { Measurement benchmarks } \\
\text { Can you estimate the height of a large object? } \\
\text { Can you use a benchmark and operation? }\end{array}$ \\
\hline
\end{tabular}

Sowder (1994) wrote that number sense helped students to deal with problems " holistically " (p. 144), to have a feeling about how to solve problem without using a particular procedure, and to monitor and control their solution activity. Carroll (1996) asserted that good mental computation and estimation ability is evidence of number sense and also enhances the development of number sense in addition to improving metacognitive skills. If mental and estimation computation are taught using a problem-solving approach rather than as a sequence of strategies or skills, students tend to invent their own strategies and then mental and estimation computation will involve higherorder thinking.

\section{Number Sense Related To Preservice Teachers}

Research suggests that elementary teachers effect both the achievement and the attitude of students in mathematics. In fact, elementary teachers play an important role in the early mathematical environment for students. Results of Leinhardt and Smith's (1985) study of expert teachers indicate considerable variability in teachers' knowledge of fundamental rational number concepts. Gliner's (1991) study of estimation performance of prospective elementary teachers indicated lower performance than should be reasonably expected of a mathematically literate eighth grader. The results show that school learned algorithms could block the student's ability to perform tasks presented symbolically, even when subjects were able to successfully complete the same task perceived to be from real life. An analysis of the prospective teachers' explanations of their solution efforts indicates that the difficulties lie not in the ability to estimate, but instead a lack of general number sense (Gliner,1991). Furthermore, the research data implies emphasis on rule -bound mathematics restricts growth of a number of computational skills and keeps understanding of rational numbers isolated from realistic applications and models. Mental referents do not appear to 
be handy to most students. Markovits (1989) addressed that students are not expected to make any decisions or judgment in school mathematics, so they do not exercise their number sense or their common sense.

Post, Harel, Behr and Lesh(1991) studied the way in which intermediate teachers understand rational number concepts. They asked teachers not only to solve problems, but also to determine the conceptual and pedagogical adequacy of their explanations. The results indicate that many levels of problems exist, including: Many teachers do not know enough substantive mathematics; and only a minority of teachers able to solve problems are also able to provide coherent and pedagogical explanations. These findings suggest that it is necessary to rethink the entire elementary education process to provide time for the students to develop understanding over a long period of time. Peck and Connell (1991) concluded that when dealing with situations involving the part-whole interpretation of rational numbers, both practicing and prospective elementary teachers are unable to recognize and utilize important links between concepts, and are unable to effectively aide students' construction of mathematical concepts. Joyner(1994) analyzed elementary teachers' knowledge of rational number concepts through an instrument that was designed to glean information about these computational processes and reasoning. Elementary teachers were asked to perform computations and to provide symbolic, pictorial, or word models for real life and symbolic problems. Models of typical student misconceptions were presented and the teachers were asked to judge them for their reasonableness. Practicing teachers showed no better number sense than prospective teachers in other studies. Joyner (1994) concluded that the teachers confused place value concepts with whole number addition and fraction addition, that they had a poorly developed referent system for rational numbers, and that they lacked number sense with fractions.

In a the study of preservice teachers' understanding of the operation of division, Ball (1990) found that their understanding relied on rules and was unrelated to other mathematical operations. Five of nineteen participants generated inappropriate representations for division by fractions, while only five were able to provide appropriate representations. Eight participants were unable to construct any representation at all. They either recognized the conceptual problem or recognized that their initial response represented division by 3 rather than by $1 / 3$. The data reveals that preservice teachers apply well-ingrained whole number rules, instead of weakly understood fraction and decimal concepts, to draw false conclusion about rational number representations, such as 0.45 is greater than 0.5 because 45 is greater than 5 (Ball, 1990).

Johnson (1998) conducted a study yielding more evidence that prospective teachers' general number sense and rationale number concept knowledge are inadequately developed. These students, resist looking at mathematics in creative, non-algorithmic ways. The instrument was administered to prospective elementary teachers who have completed their formal mathematics training and were enrolled in the methods of teaching elementary mathematics. The participants were asked to generate solutions using mental arithmetic and then explain why their answers were correct without resorting to algorithmic procedures. Further analysis of responses identified common misconceptions held by prospective elementary majors which included:

- $\quad$ The belief that the fraction having the larger denominator is always large;

- $\quad$ The belief that two fractions that are almost equal are equivalent;

- $\quad$ The confusion about decimal place value;

- The use of flawed algorithms, such as multiplying fractions by using a common denominator and multiplying numerators; and

- $\quad$ The belief that area models must be rectangular or regular in order to find a fractional portion.

In contrast, the findings of Troutman's (1994) study suggests that prospective elementary teachers were able to manipulate symbols algorithmically and find mathematical products, but were not able to create intuitive algorithms, arguments, or models that rely on number sense and mathematical reasoning.

\section{Constructivist Perspective}

The constuctivism perspective views learning as a product of organization. Piaget stated "intelligence organizes the world by organizing itself " (Von Glasersfeld, 1989,p. 136). The Piagetian, psychological proponents 
of constructivism, see the meaning-making process as individualistic with the purpose of constructive teaching being to lead toward higher levels of understanding and analytic capabilities. For example, Schifter and Simon (1992) describe the goals of constructivist mathematics instruction as teaching the " ...nature of mathematics inquiry the modes of generating knowledge that are characteristic of discipline" (p. 187). In order to reach these higher levels, student must be actively engaged in reconstructing their existing understandings by restructing their cognitive map. The teacher encourages this in two ways: facilitating an environment in which students undergo a certain amount of cognitive dissonance, and devising tasks that hopefully lead to a reorganization of existing cognitive maps (Richardson, 1997).

This has been translated into instructional practices such as hands-on activities ( for example, the use of manipultives). The engagement of students in tasks that are meant to challenge their concepts and thinking processes are included. Clements and Battista (1990) define constructivism as an epistemology which follows basic tenets:

- $\quad$ Knowledge is actively created by the student.

- New mathematical knowledge is created by reflection on physical and mental actions.

- $\quad$ There is no one true reality-each person has their own reality based upon their interpretation.

- $\quad$ Learning is a social process; meaning is negotiated.

- $\quad$ Students learn when allowed to explore. They tend to memorize when knowledge is "dished out" to them.

Vygotsky (1986) noted that individual development cannot be understood without reference to the interpersonal and institutional surrounding in which the child is situated. According to Vygotsky(1978), the transformation of intermental plane to intramental plane occurs within the Zone of Proximal (or potential) Development. This is the distance between the lower level, where the student or child works independently, and the upper level, where the child completes the task with assistance from an adult or more experienced peer. Studies addressing the Zone of Proximal Development are based on social interaction in a dyad, where the role of the adult, teacher or more experienced peer is to guide or provide scaffolding for the child, student, or less experienced peer. Vygotsky (1986) describes children as active in their own development and as creating knowledge of the world through activity. The active role of the child allows for the transformation of knowledge. Therefore, knowledge is dynamic and is created, examined, and transformed rather than merely transmitted, whole, from the adult to the child.

The essence of constructivism is the learner's knowledge-building process ( Fosont,1996). Understanding knowledge acquisition therefore seems to be a central task in attempting to define the role of constructivism in teacher education. Contructivist teaching typically involves more student-centered, active learning experiences, more student-student and student-teacher interaction, and more work utilizing concrete materials and solving realistic problems (Shuell,1996). Research into the conceptions and understandings that students hold following instruction (White,1988) has generated a demand for teaching that is informed by a constructivist perspective on learning.

Many preservice education programs that have been described include such a perspective (Wideen, MayerSimith and Moon,1994). But adopting such an approach involves considerable conceptual change for most preservice teachers, and achieving this is not necessarily easy (Kagan,1992; Northfield, Gunstone and Erickson,1996). Research studies indicate mixed results in promoting change in preservice teachers' beliefs and practices. Hollingsworth (1989) found that preservice teachers enrolled in a constructivist teacher education program did undergo conceptual change and acquire new beliefs, but that entering beliefs were influential in mediating this process. However, McDiarmid (1990) reported that when elementary preservice teachers were confronted with mathematics instruction that challenged their assumptions about teaching, some reflected on and re-evaluated their beliefs, while other resisted and retained their conceptions.

\section{Constructivist-Based Instruction}

As one's number sense knowledge is developing through intuitive or informal methods in an individual's everyday life, one is also learning formal mathematics in school. These experiences may result in the growth of 
number sense. It is also clear that many children tend to use memorized rules and computational methods involving written symbolism when they are in school or solving school-assigned problems (e.g., NAEP, 1983; Silver, 1994; Sowder \& Kelin, 1993; and Van de Walle \& Watkins, 1993). This traditional emphasis on computational skill mastery has a tendency to narrow and compartmentalize children's numerical thinking rather than to integrate it and make it flexible (Case, 1989).

Cobb and Merkel (1989) believe that "thinking-strategy instruction" (p.80) is an essential component in formal mathematics. Through formal instruction, teachers encourage children to invent thinking strategies when answering mathematical problems. This promotes the conceptual understanding of mathematics. Cobb and Merkel (1989) state that "when thinking strategies are viewed as thought processes, children's improved learning of the basic facts can be seen as the result of a more profound development-the construction and organization of relationships among numbers" (p. 71). In fact, the teaching of thinking strategies is highly related to the development of mental computation and computational estimation strategies.

Yackel, Cobb, Wood, Wheatly, and Merkel (1990) addressed that "social interaction in the classroom plays a crucial role as children team mathematics" (p. 20). They found that when children cooperative learning mathematics in the classroom and children are given opportunities to explain their thinking strategies, they can construct their own mathematics. Kamii (1990) emphasizes the importance of "constructivism" for teaching arithmetic and argues the danger of teaching standard arithmetic algorithms to children. She states that "we must focus our goals and objectives on children's thinking rather than on their writing correct answers" and "we must encourage children to agree or disagree among themselves rather than reinforce right answers and correct wrong ones" (pp. 26-27). Kamii and Lewis (1991) reported results that the achievement test scores for the traditional group and the constructivist group were almost identical. However, children in the constructivist group were significantly better in explaining their thinking strategies, solving nontraditional number problems, and applying mental strategies than the traditional group of students. For example, forty-eight percent and sixty percent of the constructivist group of students could correctly utilize the mental strategies to answer $98+43$ and $3 \times 31$, whereas only seventeen percent of traditional group students mentally calculate both of the problems (Kamii and Lewis ,1991). Researchers suggest that when problem-centered instructional approach mathematics and children are given opportunities to explain their thinking strategies, they can construct their own mathematics. For instance, when children were asked to solve $49+53$, they can develop a variety of solution methods such as (Kamii and Lewis ,1991; Yackel et. al., 1990) :

- $\quad 40$ plus 50 -- 90, then 9 plus 1 more would be 100 , plus 2 more would be 102.

- $\quad$ You have 53, 10 more is 63, plus 10 more-73, plus 10 more 83, plus 10 more, plus 9 . . 102.

- $\quad$ See, 49 and 50 more is 99 , then add 3 makes 102.

- 40 plus 50 is 90 and 9 plus 3 is 12. Put all those together and I came up with 102 (Yackel, et. al., p. 14).

In an assessment of a problem-centered mathematics project, Cobb, Wood, Yackel, Nicholls, Wheatly, Trigatti, \& Perlwitz (1991) found that the computational performance was comparable for project and nonproject second grade students. However, "there were qualitative differences in arithmetical algorithms used by students in the two groups. Project students had higher levels of conceptual understanding in mathematics; held stronger beliefs about the importance of understanding and collaborating; and attributed less importance to conforming to the solution methods of others" (p. 3). They suggest that the problem-centered instructional approach can encourage the discussion of teacher and students and make sense of mathematics learning. These findings were from recent research of over forty primary-grade teachers who were involved in a project that also focuses on a problemcentered approach to mathematics.

Oliver, Murray, and Human (1990), found that "many children are highly creative in inventing their own powerful nonstandard algorithms based on sound level 3 understanding of number and numeration" (p. 298). In this instructional experiment, curriculum was used to encourage children to develop their own thinking strategies. The research results of Olivier et al.(1990) show that children in the experimental group more frequently utilized their own thinking strategies to solve problems than the control group of students. 


\section{Problem-Solving-Based Classrooms}

Recommendations for the Preparation of Teachers of Mathematics (Committee of the Mathematical Education of Teachers and the Mathematical Association of America, 1991) document describes collegiate mathematical content and experiences for prospective and practicing teachers of the 1990's. It recommends that preservice elementary school teachers should be presented with opportunities in their collegiate courses to do mathematics: explore, analyze, construct models, collect and represent arguments, and solve problems. The document further recommends preservice elementary school teachers discuss concepts, reflect on their thinking, pose questions, answer questions, present logical arguments, and critique the work of other students to help them develop pedagogical content skills necessary for teaching mathematics.

The math course used in this research is taught in a constructivist manner. The focus of the teaching is student thinking and mathematical activity. The students, mostly preservice elementary school teachers, take part in hands-on activities utilizing manipulatives and technology (McNernery, 1994 ) and learning mathematical ideas in much the same way their future students may learn mathematics. This type of instruction meets many of the goals of the NCTM Professional Standards. As the preservice teachers experience mathematics with a focus on student thinking and mathematical activity, they are able to construct meaning on their own, leading to a better understanding of mathematics (NCTM,1989, b).

Initial studies regarding the effects of teaching problem solving strategies focused on the end-product of problem solving. Lucas (1974) studied the effect of teaching heuristic instruction on college calculus students. The instruction was based on Polya's four-step model. "Looking back " is one of the major steps in problem solving process (Polya, 1945). In estimating, this can be compared to judging the reasonableness of a given answer. Many researchers (Carpenter et al., 1980; Schoen and Oehmke,1980; Smith,1989) found this to be one of the key steps that students omit. The reviews of NAEP (Carpenter et al., 1980) found that students at ages 9 and 13 did not check the reasonableness of their results. This concurs with Schoen and Oehmke's (1980) finding that students in grades five through eight, observed in the process of problem solving, rarely looked back to see if their solution made sense. Smith (1989) conducted a study using 225 eighth grade students on the efficiency of heuristic training course on problem solving. Results indicate that the problem training group showed a significant improvement in mathematical problem-solving performance over the non-training group.

Schoenfeld (1992) notes the results of studies by Silver in 1979 and Heller and Hungate in 1985. Their research pointed out that students can be taught to focus specific strategies which related to various problem-solving exercises. They recommend that (a) tacit processes should be made explicit to the students, (b) students should be involved in talking about processes, (c) students should be provided with guided practice, (d) students should learn the components of Polya's strategies, and (e) teachers should emphasize both the qualitative understanding and specific procedures involved in the problem solving process. However, research has not always provided evidence that teaching heuristics has a significant positive impact on the students' problem-solving skills. Lester (1994) claimed there is little supportive research to claim that teaching students about problem-solving strategies and heuristics and phases of problem solving improves students' ability to solve mathematics problems in general.

\section{Methodology}

The purpose of this study was to investigate the effect of an undergraduate problem-solving-based mathematics course on the number sense of preservice elementary school teachers.

\section{Population And Sample}

The population of this study consists of preservice elementary school teachers at a mid-sized, four-year, state university in a mid-sized town in the Rocky Mountain region. The sample was composed of students in six intact entry-level mathematics sections of a course populated by preservice elementary school teachers. 155 participants from these six classes completed data collection tasks during the Spring 2002 semester for the study. 


\section{Research Design}

Research designs using a control group could not be used for this study, as the problem-solving-based classroom is the required method by the institution to teaching this mathematics class. Thus, students were not asked to volunteer to be in any classroom which does not use the problem-solving-based approach. The research design can be classified as a modified "One-group Pretest-Posttest Design" ( Campbell \& Stanley,1963). The six combined classes form "one-group" with present/posttest corresponding to the pre-post-survey. Although the six classes were taught at different times during the day there are no significant demographic differences between classes. Therefore, the six classes will be treated as one group. This quasi-experimental design is identified as O X O. Here, the " $\mathrm{O}$ " signifies the collection of data through surveys. The " $\mathrm{X}$ " indicates the actual course instruction. While there were a continuous treatment (the problem-solving-based classroom), in a sense, there was a point in the course where number sense was the formal topic. For the purposes of this design, the treatment $(\mathrm{X})$ was considered to be the instruction and classwork on the number system. Since there were no requirements of this study as to instructional teaching style, there may be a teacher effect threat to internal validity. Therefore, the researcher reported group means of performance and group means was compared on the Number Sense Test. Also the researcher has met with the instructors before the semester began to outline the proposed study, solicit suggestions, and answer questions. T-tests were used to compare the paired changes (pretest to posttest) in number sense domain across time.

\section{Instrument}

The Number Sense Test (NST) was developed by Yang (1997) for grade 6 and 8 students in Taiwan. The 25 item NST includes whole number, fraction, and decimal items as well as the four basic operations. According to Yang, the split-half reliability of the NST is over 0.80 for both $6^{\text {th }}$ and $8^{\text {th }}$ grade of students. Figure 4 provides the framework of NST items by number domain and four basic operations. Table 2. shows three items.

Table 2.

Sample Of Number Sense Test Items

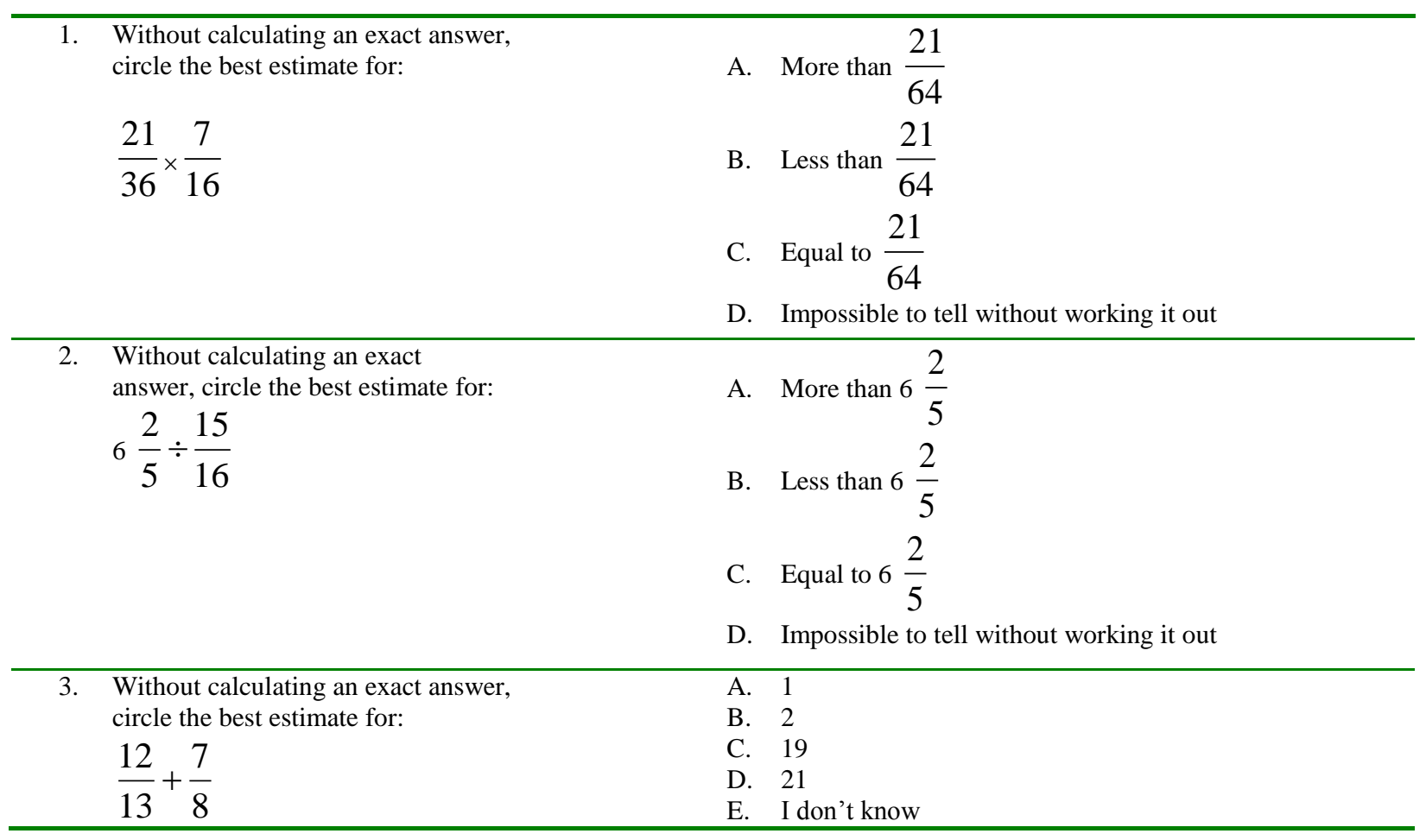


Yang (1997) reported NST items 19, 22 and 24 were selected from the Number Sense Group test items constructed by Mcintosh, Reys, \& Reys (1997). Item 4 was selected from the Second National Assessment of Educational Progress instrument ( Carpenter, Corbitt, Kepner, Lindquist, \& Reys,1980). Item 13 was selected from the study of Markovits and Sowder (1994). The remaining NST items were created by Yang (1997). Several items are similar to those from the above sources with variation in numbers and operations. Table 3 presents the items contained in the NST.

Table 3.

The Framework Of Number Domain And Four Basic Operations On The NST

\begin{tabular}{lcccc}
\hline & Addition & Subtraction & Multiplication & Division \\
\hline Whole Numbers & 9,12 & 21 & $11,23,25$ & 14 \\
Decimals & 18 & 19 & $1,7,8$ & $5,15,17$ \\
Fractions & 4,6 & $10,13,22$ & $2,21,24$ & 3,20 \\
\hline
\end{tabular}

\section{Reliability Of Instrument}

This researcher utilized the Statistical Package for Social Science (SPSS) to calculate the Cronbach's alpha coefficient in order to examine the reliability of the Number Sense Test (NST), which was used in this study. The Cronbach's alpha coefficient reliability for the Number Sense Test (NST) is 0.77. The Cronbach's alpha coefficient reliability of instrument has demonstrated consistent reliability for measures of internal reliability.

\section{Data Collection Procedures}

In the beginning of the semester, instruments used to collect data was, the Number Sense Test (NST). Calculator use was allowed. At the beginning of the semester, the Number Sense Test was given to all classes. At the end of the semester (14 week later) the Number Sense Test was re-administered to the six classes by the researcher or instructors.

\section{Number-Sense Test}

During the first week, a 25-item Number Sense Test was given to the students. Students were given a copy of the NST and instructed not to begin work until told to do so by the researcher. The researcher and instructors were provided with general instructions and answer questions from students. Students were asked to obey the rules of this test: timing per item is about 45 seconds and students were told not to spend too much time on any one question.

\section{Data Analysis Procedures}

\subsection{Scoring Data}

Yang (1997) supported reliability of NST in that the instrument was administered multiple times and the data analyzed. Each item of the NST is assigned a maximum of 2 points. On items where the subject gave the correct answer, the item will be awarded 2 points. If there is no response or if the response is incorrect, this item will be assigned 0 points. However, items 11, 13, 18, 21 and 25 have a possible point range of 0 to 2 points. For example, items 11 and 13 require the subject to give correct answers and correct explanations. These items are assigned 2 points. If the answer is correct, but the explanation is unclear or if there is no explanation, this item will be assigned 1 point. If both the answer and reasons are incorrect, this item is assigned 0 points. Similarly, if the answer is correct, but the reasons are incorrect, the item also will be assigned 0 points (Yang, 1997). The total possible score of the NST is 50 points. 


\subsection{Analyzing Data}

\subsubsection{Beginning of the Semester}

Students' responses were judged to decide whether the characteristics of "number sense" are correctly used by preservice teachers. One example from the pilot study was coded as follows:

Table 4.

One Example From The Pilot Study Was Coded

\begin{tabular}{|l|l|l|}
\hline \multicolumn{1}{|c|}{ Questions } & \multicolumn{1}{|c|}{ Responses } & \multicolumn{1}{|c|}{ Coded Category } \\
\hline $\begin{array}{l}\text { How many decimals are there } \\
\text { between } 1.42 \text { and } 1.43 ?\end{array}$ & $\begin{array}{l}\text { There are infinite decimals between } 1.42 \text { and } \\
1.43 .1 .421,1.422,1.423, \ldots .1 .429 \text { are } \\
\text { between } 1.42 \text { and } 1.43 .\end{array}$ & $\begin{array}{l}\text { This was judged as correct use of } \\
\text { the number magnitude }\end{array}$ \\
\hline
\end{tabular}

\subsubsection{End Of The Semester}

At the end of the semester, data from students who did not provide data for all measures were not used. All four measures were scored and descriptive statistics provided for each student. The paired NST changes scores were calculated and t-tests were performed at the end of the semester to determine if there are any significant changes in the NST scores between any of the observations.

\section{Results}

This section contains the analysis of the quantitative data collected from all six sections of the course. The total participants in this study were one hundred fifty-five college students, who enrolled in an undergraduate problemsolving-based mathematics course during Spring Semester 2002.

\subsection{Number Domain Related Results On NST Items}

The NST included items representing three number dimensions: Whole Numbers, Decimals, and Fraction numbers. Table 5 displays the percents of correct responses and standard deviations on the NST by number domains for the one hundred fifty-five participants. The pretest data show that the number domain of Fraction percent of the Number Sense Test was relatively low when compared with Whole Number (42.5\%) and Decimal (43.81\%).

Table 5.

Mean And Percent Of Correct Responses Of Pretest On Number Domain Items For NST.

\begin{tabular}{lccccc}
\hline Number Domain & Number of Items & Possible Scores & Mean & Standard Deviations & Percent \\
\hline NST Whole & 6 & 12 & 5.10 & 2.67 & 42.50 \\
NST Decimal & 8 & 16 & 7.01 & 3.59 & 43.81 \\
NST Fraction & 11 & 22 & 8.04 & 4.15 & 36.50 \\
\hline
\end{tabular}

Table 6 displays the mean, percent of correct responses and standard deviation on the NST by number domains for the posttest. The posttest data show the number domain of Fractions as 56.72. The percent of correct responses on the Number Sense Test was relatively low as compared with the Whole Number (58.00) and Decimal (59.06) the percent of correct responses. 
Table 6.

Mean And Percent Of Correct Responses Of Posttest On Number Domain Items For NST

\begin{tabular}{lccrcc}
\hline Number Domain & Number of Items & Possible Scores & Mean & Standard Deviations & Percent \\
\hline NST Whole & 6 & 12 & 6.96 & 2.27 & 58.00 \\
NST Decimal & 8 & 16 & 9.45 & 3.25 & 59.06 \\
NST Fraction & 11 & 22 & 12.48 & 4.86 & 56.72 \\
\hline
\end{tabular}

\subsection{The Statistical Analyses For Research Questions}

What are the effects of a problem-solving-based mathematics course on the number sense of preservice elementary school teachers? According to this research question, null hypotheses were stated: H01 stated that there is no significant difference in the measure of preservice elementary school teacher number sense collected at the beginning and end of the problem-solving-based mathematics course, at the $\alpha=0.01$ level. In order to answer this question, a t-test was used to compare the NST performance of pretest and posttest. Table 7 summarizes the t-test results between the mean scores on the NST Number Domain Items in the pretest and posttest. The resulting change in means are displayed in Table 8.

Table 7.

The T-Test Results On The NST Number Domain Item

\begin{tabular}{lccc}
\hline & Mean & Std Error & t Value \\
\hline NST & 8.805 & 0.586 & $15.023^{*}$ \\
NST Whole & 1.503 & 0.2516 & $5.975^{*}$ \\
NST Decimal & 2.445 & 0.2952 & $8.283^{*}$ \\
NST Fraction & 4.858 & 0.352 & $13.803^{*}$ \\
\hline
\end{tabular}

Table 8.

Pre/Post Means For The NST Number Domain Item

\begin{tabular}{lccr}
\hline & Possible scores & Pretest Mean & Posttest Mean \\
\hline NST & 50 & 20.08 & 28.89 \\
NST Whole & 6 & 5.10 & 6.96 \\
NST Decimal & 8 & 7.01 & 9.45 \\
NST Fraction & 11 & 8.04 & 12.48 \\
\hline
\end{tabular}

The t-test results indicated that there was a statistically significant difference between the NST mean score of the pretest and posttest ( $\mathrm{p}=0.0001$ ), at the 0.01 significance level. Using $\alpha=0.01$ as the pre-study determined level of testing, there was sufficient evidence to reject the null hypothesis regarding differences in the measure of preservice elementary school teacher number sense collected at the beginning and end of the problem-solving-based mathematics course.

Furthermore, the t-test results indicated that there was a statistically significant difference between the Number Domain Item mean score of the pretest and posttest ( $p=0.0001$ ), at the 0.01 significance level. Using $\alpha=0.01$ as the pre-study determined level of testing, students demonstrated significant change in Number Domain Items.

As a student's mathematical experiences and knowledge increased, it is reasonable to conclude that the student's number sense capabilities also mature and develop. The increased mathematics knowledge of students led to 
an increase in number sense performance. This might be due to students learning concepts in a problem-solving-based mathematics course during this semester.

\section{Discussion, Implications, And Recommendations}

As reported in result section, statistically significant changes from pretest to posttest were found in the Number Sense Test, and change was significant at the $\alpha=0.01$ level. Students definitely improved in their mental computational skills and number sense. It appears that being in a problem-solving-based mathematics course did result in additional necessary practice which helped them to improve their number sense This study supports the findings confirms that the problem-centered instructional approach can encourage the discussion of students and make sense of mathematical learning (Cobb, Wood, Yackel, Nicholls, Wheatly, Trigatti \& Perlwitz ,1991). This results indicate the focus of teaching is student thinking and mathematical activity, taking part in hands-on activities, utilizing manipulatives, and learning mathematical ideas so that preservice elementary teachers may learn mathematics. The process of working with hands-on activities help students develop backup strategies that can be used when they become confused with the mechanisms of newly learned strategies or when they want to be certain that computations are indeed correct. As the preservice elementary teachers experience mathematics with a focus on student thinking and mathematical activities, they were able to construct meaning on their own, leading to a better understanding of mathematics (NCTM, 1989 a).

We should encourage preservice elementary school teachers to use multiple solution strategies. We should develop computational algorithms logically so students see that the algorithms are simply shortcuts for timeconsuming procedure (such as multiplication for repeated addition and division for repeated subtraction) or alternatives for other representations (as decimal for fractions). Preservice elementary school teachers appear to benefit more from opportunities to explore different number patterns and creating different strategies, instead of being encouraged to rely only on exact answers. They should not only learn how to calculate an exact answer, but also to develop a better understanding of number meanings and comprehending relationships between numbers and operations. This is desirable in addition to learning how to calculate an exact answer.

As we move to implement the NCTM's Principles and Standards for School Mathematics (2000), we must, first and foremost, realize that the teaching of mathematics must strive to reach all students. This may not occur until all our teachers realize that teaching mathematics is much, much more than teaching paper-and-pencil algorithms. This study found that many preservice elementary teacher subject of research are not ready to be immersed into a curriculum that reflects the vision of less emphasis on paper-and-pencil computation and more emphasis on number sense and mental arithmetic stated in the NCTM Standards. Therefore, specific steps need to be taken in order to assure that future teachers have a proper conceptual understanding of new definitions of computation and number sense as recommended by the NCTM (2000) and have the skills to implement it.

Based on the findings of this study and the review of the literature, the following Elementary Education Teacher program recommendations are made:

Teacher preparation courses should provide preservice teachers with a strong foundation in historical and current thinking on mathematics education and prepare them to implement the recommended curricular changes. The NCTM Standards (2000) encourages colleges and Universities to reconsider their teacher-preparation programs in light of the NCTM curricular recommendations. We need to equip the teachers of the future with the needed knowledge, skills and attitudes that will enable them to aid in the development and subsequent teaching of the mathematics curriculum recommended by the many panels and commissions of the 21th century (NCTM, 2000).

When preservice elementary teachers become aware of the importance of using mental arithmetic and number sense, they may then develop the needed strategies necessary to become competent with this idea. This information concerning the background for the changing perspective of computation will also have important consequences for the way preservice teachers teach and also for those occasions when they have to inform and convince peers, administrators, and parents about the reasons underlying the increasing emphasis on number sense and mental arithmetic. 
Number sense is a major theme of the NCTM Principles and Standards for School Mathematics (2000). Colleges and universities must help students develop number sense ideas. In particular, the ability to recognize the relative magnitude of numbers, ability to deal with the absolute magnitude of numbers, ability to link numeration, operation and, relation symbols in meaningful ways, ability to understand the effect of operations, ability to perform mental computation through " invented " strategies that take advantage of numerical and operational properties, ability to use numbers flexibly to estimate numerical answers to computations and to recognize when estimate is appropriate, and a disposition towards making sense of numbers. If preservice teachers have a good number sense, they may be likely to select appropriate computational methods and they may be more confident about how they work with numbers. With this confidence, they may be better teachers because they can potentially help their students become confident with numbers.

\section{Recommendations For Future Studies}

The university of this study requires three courses in the mathematics sequence for all preservice elementary school teachers. Charting the progress of, and looking for changes in number sense skills of students would be a good follow-up longitudinal study. Another related research is to replicate this study with a different demographic sub-population of preservice elementary school teachers to see if the results remain consistent. If many preservice elementary school teachers lack number sense, then the results from such studies could support a new component of instruction across many teacher preparation institutions nationally and internationally.

The present study could be repeated using preservice secondary science teachers and in-service elementary teachers as participants to see if the results are similar across groups. Further, it might be interesting to see if inservice teachers who teach elementary mathematics have more "number sense" than preservice teachers.

Teachers of the first mathematics methods course of the three course sequence should be aware that their students are sometimes deficient in unexpected areas. The poor performance on the questions involving fractions is an example. One possible reason for poor results in this area is that many preservice elementary school teachers' knowledge of fractions is rule-based, whereas the research mathematics instrument meaning in mathematical content. Fractions are a topic that has often caused difficulty for many students. More time spent on developing conceptual knowledge of this topic in the required coursework of preservice elementary teachers should be beneficial to them.

In the present study, I have provided evidence that an elementary mathematics methods course can improve number sense of preservicve elementary school teachers. Overall, these results provide hope and encouragement for instructors for elementary school teacher courses as they face the challenge of preparing preservice teachers to reform mathematics education in the next millennium. Hopefully, this study will inspire other mathematics education researchers to continue to learn more about this topic and will help preservice elementary school teachers develop better number senses not only for their own benefit, but for their students.

\section{References}

1. Artzt, A. F. (1999). "Cooperative learning in mathematics teacher education”, Mathematics Teacher, 92(2), 11-17.

2. Ball, D .T. (1990). "Breaking with experience in learning to teach mathematics: the role of a preservice method course", International Journal of Mathematics Education, 10, (2), 10-16.

3. Carpenter, T. P., Corbitt, M. K., Kepner, H.S., Lindguist, M. M., \& Reys, R. E. (1980) . "Results and implications of the second NAEP mathematics assessment: Secondary school", The Mathematics Teacher, 73, p.329-338. (b).

4. Carroll, W. (1996) "Mental computation of students in a reform-based mathematics curriculum", School Science and Mathematics, 96(6), 305-311.

5. Clements, D.H., \& Battista, M. T. (1990). "Research into practice. Constructivist learning and teaching", Arithmetic Teacher, 38(1), 34-35. 
6. Cobb, P. \& Merkel, G. (1989). "Thinking strategies: Teaching arithmetic through problem solving”, in New Direction for Elementary School Mathematics, 1989 Yearbook of the National Council of Teachers of Mathematics (pp. 70-84). Reston, VA: National Council of Teachers of Mathematics.

7. Cobb, P., Wood, T., Yackel, E., Nicholls, J., Wheatly, G., Trigatti, B., \& Periwitz, M. (1991). “Assessment of a problem-centered second grade mathematics project", Journal for Research in Mathematics Education, $22(1), 3-29$.

8. Cuff, C (1993). "Beyond the Formula-Mathematics education for prospective elementary school teachers", Education,114_(4),221-223.

9. Fosnot, C. (1996). (Ed) Constructivism: theory, perspectives and practice, New York, Teacher College Press.

10. Gliner, G.(1991). "Factors contributing to success in mathematical estimation in preservice teachers: Types of problems and previous mathematics experience". Educational Studies in Mathematics. 22(6), 595-606.

11. Greeno, J. G. (1989). "Some conjectures about number sense", in J. T. Sowder \& B. P. Schappelle (Eds.), Establishing, foundations for research on number sense and related topics: Report of a conference (pp. 82-84). San Diego: San Diego University, Center for Research in Mathematics and Science Education.

12. Greeno, J. G. (1991). "Number sense as situated knowing in a conceptual domain", Journal for Research in Mathematics Education, 22(3), 170-218.

13. Hiebert, J., Carpenter, T. P., \& Moser, J. M. (1982). "Cognitive development and children's solutions to verbal arithmetic problems", Journal for Research in Mathematics Education, 13(2), 83-98.

14. Hollingworth, S. (1989) "Prior beliefs and cognitive change in learning to teach", American Education Research Journal, 26(2), 160-189.

15. Howden, H. (1989). "Teaching number sense”, Arithmetic Teacher, 36(6), 6-11.

16. Hungerford, T. W. (1994). "Future elementary teachers: The neglected Constituency". The American Mathematical Monthly. 101(1),15-21.

17. Johnson, N. R. (1998). "A descriptive study of number sense and related misconceptions about selected rational number concepts exhibited by prospective elementary elementary teachers", Doctoral dissertation, University of South Florida.

18. Jones, G. S, Thornton, C. A., Putt, I. J., Hill, K. M., Mogill A. T., Rich, B.S. \& Van Zoest, L. R. (1996). "Multidigit number sense: A framework for instruction and assessment", Journal for Research in Mathematics Education, 27( 3), 310-336.

19. Joyner, V. (1994). "Elementary school teachers' knowledge of rational number concepts", (A paper presented at the annual Conference of National Council of Teachers of Mathematics in Indianapolis, Indiana).

20. Kagan , D. M . (1992). "Professional growth among preservice and beginning teachers". Review of Educational Research, 62(2),129-165.

21. Kamii, C. (1990). "Constructivism and beginning arithmetic (K-2)", in Teaching, \& Learning Mathematics in the 1990s, 1990 Yearbook of the National Council of Teachers of Mathematics (pp. 22-30). Reston, VA: National Council of Teachers of Mathematics.

22. Kamii, C. \& Lewis, B. A. (1991). "Achievement tests in primary mathematics: Perpetuating lower-order thinking", Arithmetic Teacher, 39(9), 4-9.

23. Lucas, J. F.(1974). "The teaching of heuristic problem-solving strategies in elementary calculus", Journal for Research in Mathematics Education, 5, 36-46.

24. Markovits, Z. (1989). "Reactions to the number sense conference", in J. T. Sowder \& B. P. Schappelle (Eds.), Establishing foundations for research on number sense and related topics: Report of a conference, (pp. 78-81). San Diego: San Diego University, Center for Research in Mathematics and Science Education.

25. Markovits, Z., \& Sowder, J. T. (1991). "Students' understanding of the relationship between fractions and decimals", Focus on Learning Problems in Mathematics, 13(1), 3-11.

26. Markovits, Z., \& Sowder, J. T. (1994). "Developing number sense: An intervention study in grade 7", Journal for Research in Mathematics Education, 25(1), 4-29.

27. McDiarmid, G. W. (1990). "Challenging prospective teachers during early field experiences: A quixotic understanding?”, Journal of Teacher Education, 41,12-20.

28. McGivney, R. J., \& Nitschke, J. (1988). "Is of a mnemonic for percentage problems". Mathematics Teacher, 81, 455-456. 
29. McIntosh, A., Reys, B. J., \& Reys, R. E. (1992). “A proposed framework for examining basic number sense", For the Learning of Mathematics, 12, 2-8.

30. McIntosh, A. Reys, R.E., \& Reys, B.J. (1997). "Mental computation in the middle grades: the importance of thinking strategies", Mathematics teaching in the Middle school, 2, 322-327.of Mathematics, 144-151.

31. McNerney, D. B. (1994) "A model preservice program for the preparation of mathematics specialists in the elementary school", in article, Douglas B. and Coxford, Arthur F. (Eds.), Professional Development for Teachers of mathematics: 1994 Yearbook. Reston: VA: National Council of Teachers.

32. National Assessment of Education Progress (1983). The third national mathematics assessment: Results. trends, and issue. Denver, CO: Author.

33. National Council of Teachers of Mathematics (1989 a ). Focus issue on number sense, Arithmetic is Teacher, February, 1989. Reston, VA: National Council of Teachers of Mathematics.

34. National Council of Teachers of Mathematics (1989 b). Curriculum and Evaluation Standards for School Mathematics. Reston, VA: National Council of Teachers of Mathematics.

35. National Council of Teachers of Mathematics (2000). Principles and Standards for School Mathematics. Reston, VA: National Council of Teachers of Mathematics.

36. Oliver, A., Murray, H., \& Human, P. (1990). "Building on young children's informal arithmetical knowledge", in G. Booker, P. Cobb, \& T. de Meddicuti (Eds.), Proceedings of the Fourteenth Annual Meeting: International Group for the Psychology of Mathematics Education. (Vol. 3, pp. 297-331 j. Gobiemo del Estado de Morelos, Mexico: CONACYT.

37. Polya, G. (1945). How to Solve it. Princeton: Princeton University Press.

38. Peck, D.M., \& Connell, M. L. (1991). "Developing a pedagogically useful content knowledge in elementary mathematics", (Eric Document Reproduction Service No. ED 332875).

39. Post,T.R., Harel, G., Behr, M.J., \& Lesh, S.J. (Eds.). "Intermediate teachers' knowledge of rational number concepts", in Fennama. E., Carpenter, T.P., \&Lamons, S. J .(Eds.), Integrating research on teaching and learning mathematics. (.1991, pp.177-198). Albany, NY: State University Press of New York.

40. Quinn, R. J. (1998). "The influence of mathematics methods course on preservice teachers' predagogical beliefs concerning manipulatives", The Clearing House, 71, 236-238.

41. Rasch, K. (1992). "Mathematical literacy to empower teacher education students in the $21^{\text {st }}$ century: How can this become reality?", ( ERIC Document Reproduction Service No. ED 351291)

42. Resnick, L. B. (1983). "A developmental theory of number understanding”, in H. Ginsburg (Ed.), The development of mathematical thinking (pp. 159-174). New York: Academic Press.

43. Reys, B. J. (1994). "Promoting number sense in the middle grades", Mathematics Teaching in the Middle School, 1(2), 114120.

44. Reys, R.E., Reys, B. J., Nohda, N., Emori, H. (1995). "Mental computation performance and strategy use of Japanese students in grade 2,4,6, and 8", Journal for research in mathematics education, 26, 204-326.

45. Reys, R. E. Yang, D. C. (1998). "Relationship between computational performance and number sense among sixth-and eighth-grade students in Taiwan", Journal for Research in Mathematics 29(2), 225-37.

46. Richardson, V. (1997) Constructivist teacher Education: Building New understandings, Washington, D.C.: The Falmer Press.

47. Schifter, D. \& Simon M. (1992). "Assessing teacher's development of a constructivist view of mathematics learning", Teaching and Teacher Education, (8), 2, 187-197.

48. Schoen, H. L. \& Oehmke, T. (1980). "A new approach to the measurement of problem solving skills", in S. Krulik \& R.E. Reys (Eds.), Problem solving in school mathematics. Reston, VA: National Council of Teachers of Mathematics.

49. Schoenfeld, A. H. (1992). "Learning to think mathematically: problem solving, metacognition, and sense making in mathematics", in D. Grouws (Ed.), Handbook of Research on Mathematics Teaching and Learning (pp. 334-370). New York: Macmillan.

50. Shuell, T. (1996). "Teaching and learning in the classroom context", in Berliner, D. \& Calfee, R. (Eds), Handbook of Educational Psychology, New York, Macmillan, pp. 726-764.

51. Silver, E. A. (1994). "Teaching estimation and mental computation as situated mathematical processes", in R. E. Reys \& N. Nohda (Eds.), Computational alternatives for the 21 st century: Cross cultural perspectives from Japan and the United States. 
52. Sowder, J. T. (1988). "Mental computation and number comparison: Their rotes in the development of number sense and computational estimation", in J. Hiebert \& M. Behr (Eds.). Number Concepts and Operations in the Middle Graded (pp. 182197). Reston, VA: Erlbaum.

53. Sowder, J. T., \& Kelin, J. (1993). "Number sense and related topics", in D. T. Owens (Ed.), Research ideas for the classroom: Middle grades mathematics (pp. 41-57). New York: Macmillan.

54. Sowder, J. T. \& Markovits, Z (1994). "Developing number sense: An intervention study in Grade 7", Journal for Research in Mathematics Education, 25(1), 4-29.

55. Sowder, J. (1994). "Cognitive and metacognitive processes in mental computation and computational estimation", in R. Reys \& N. Nohda (Eds.). Computational alternatives for Twenty-first Century. Reston, VA: The National Council of Teacher Mathematics.

56. Sowder. J. T., \& Schappelle, B. (1994). "Number sense-making", Arithmetic Teacher, 41(2), 342-345.

57. Van de Walle, J. A. \& Watkins, K. B. (1993). "Early development of number sense", in R. J. Jensen (Ed.), Research ideals for the classroom: Earl childhood Mathematics (pp. 127-149). New York: Macmillan.

58. Von Glasersfeld, E. (1989). "Cognition, construction of knowledge, and teaching”. Synthese, 80, 121-140.

59. Vygotsky, L. S (1978) . Mind in society: the development of higher psychological process, Cambridge, MA: Harvard University Press.

60. Vygotsky, L. S (1986). Thought and Language, Cambridge, MA: The MIT Press.

61. White, R.T. (1988). Learning Science. Oxford, Basil Blackwell.

62. Wideen, M. F., Mayer-Smith, J. A. \& Moon, B.J. (1994). "The research on learning to teach: Prospects and problems", paper presented at the annual meeting of American Educational Research Association, San Francisco, CA.

63. Yackel, E., Cobb, P., Wood, T., Wheatly, G., \& Merkel (1990). "The importance of social interaction in children's construction of mathematical knowledge", in Teaching \& Learning Mathematics in the 1990s, 1990 Yearbook of the National Council of Teachers of Mathematics (pp. 12-21). Reston, VA: National Council of Teachers of Mathematics.

64. Yang, D. C. (1997). Number Sense performance and strategies possessed by six-and eighth-grade students in Taiwan. Doctoral Dissertation, University of Missouri.

Notes 
Notes 